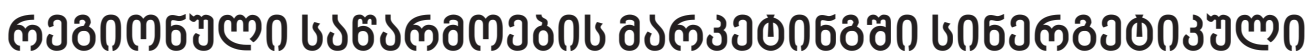

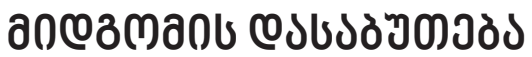

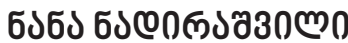

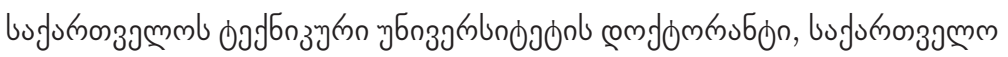

https://doi.org/10.35945/gb.2017.04.024

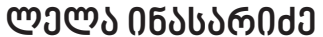

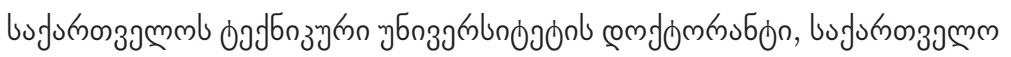

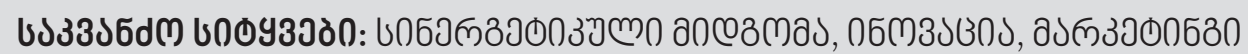

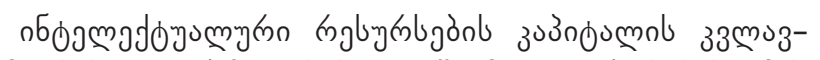

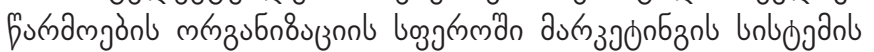

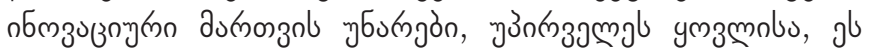

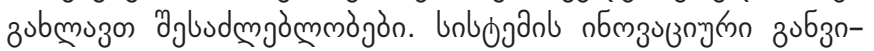

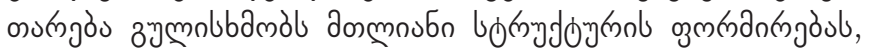

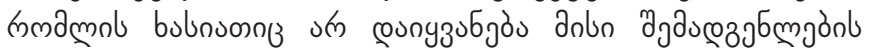

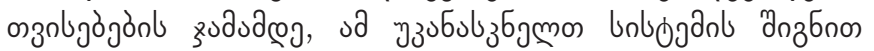

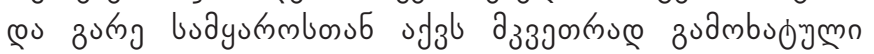
चुnonng

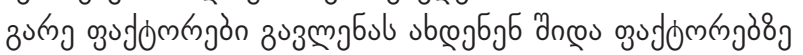

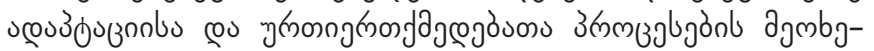

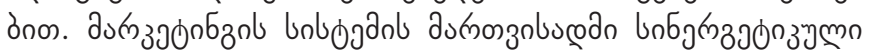

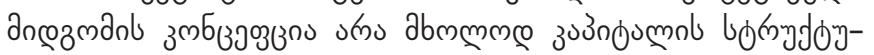

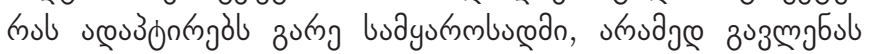

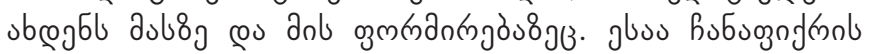

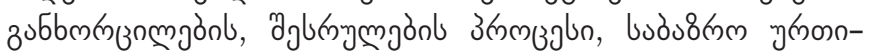

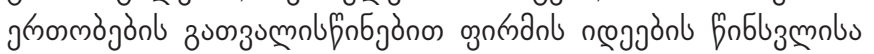

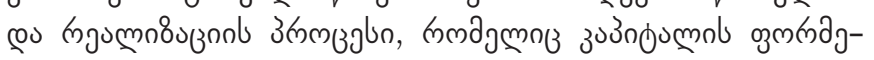

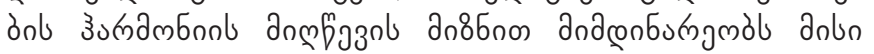

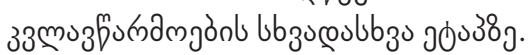

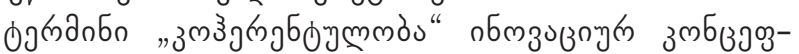

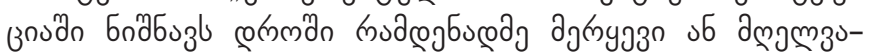

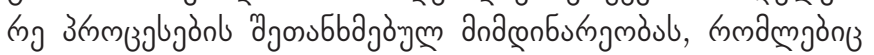

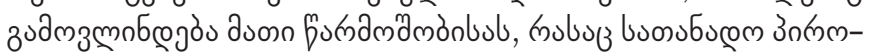

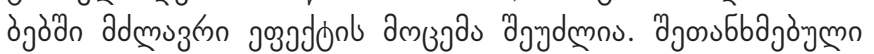

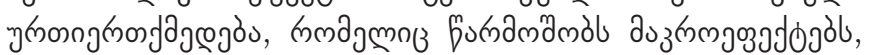

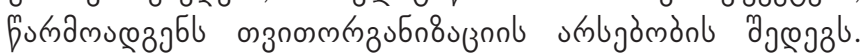

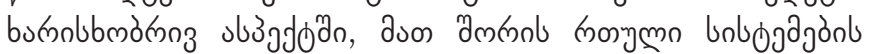

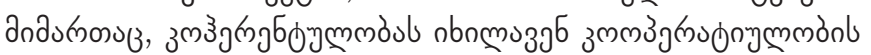

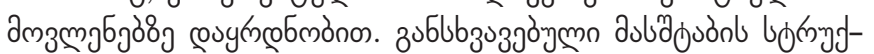

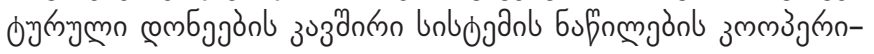

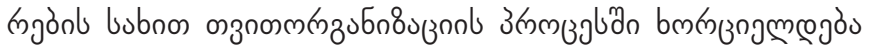

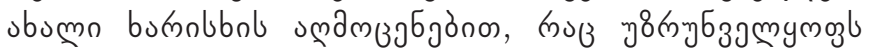

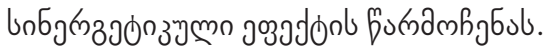

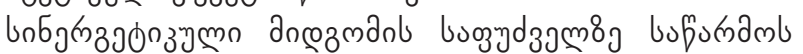

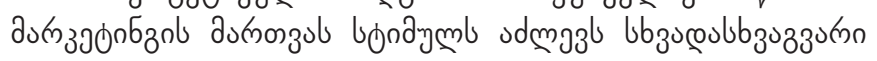

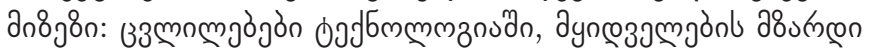

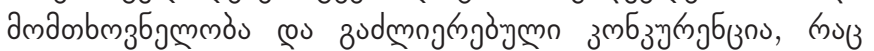

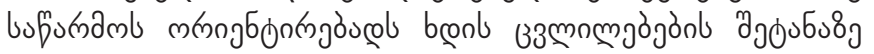
s

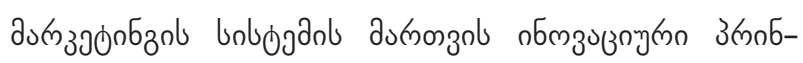

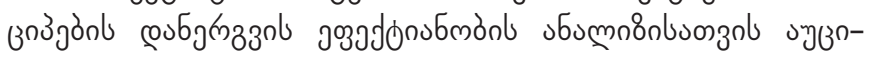

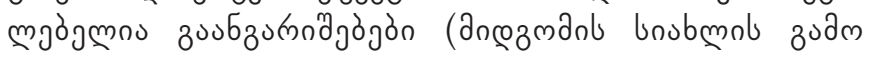

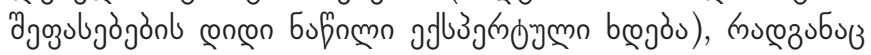

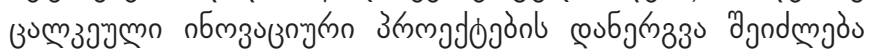

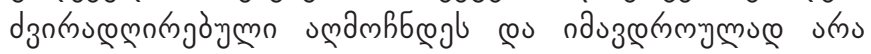

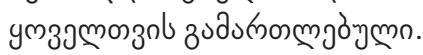

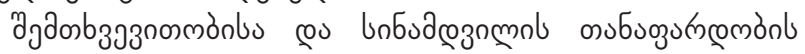

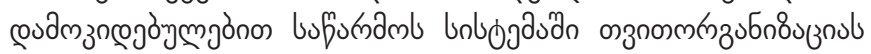

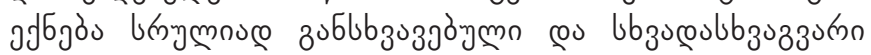

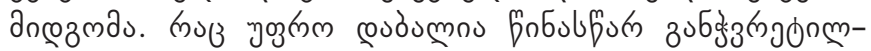

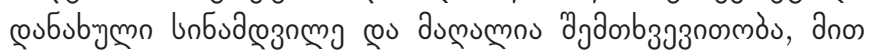

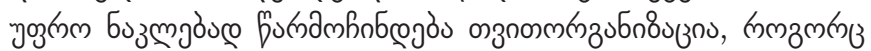

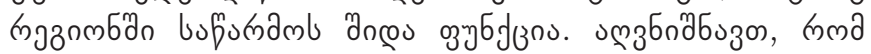

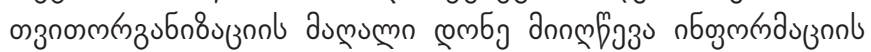

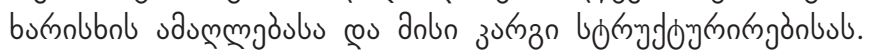

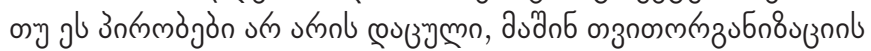

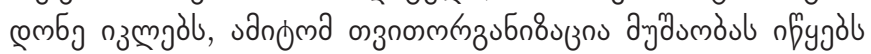

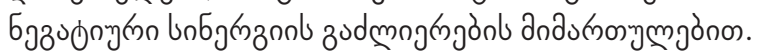

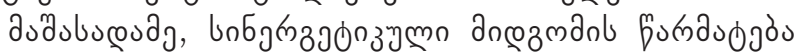

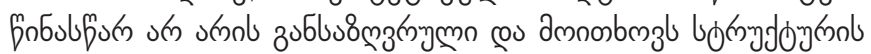

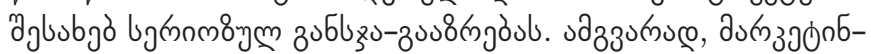

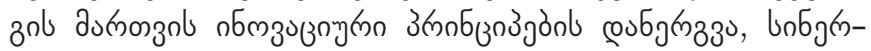

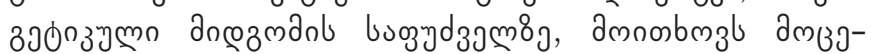

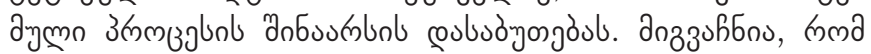

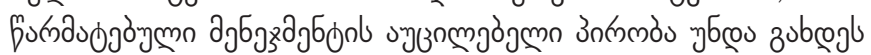

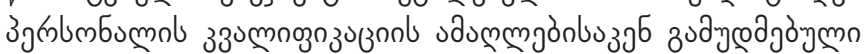

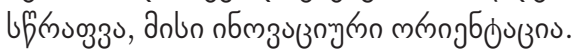

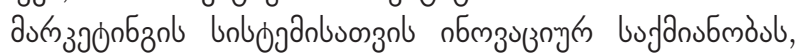

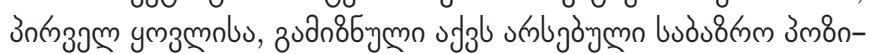

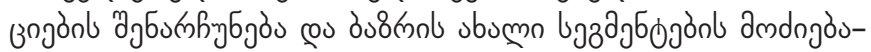

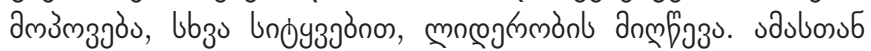

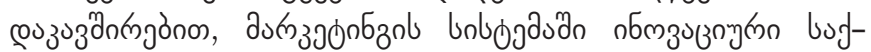

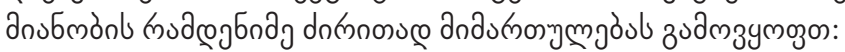

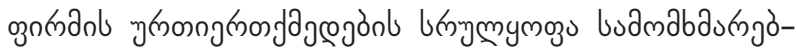

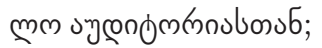

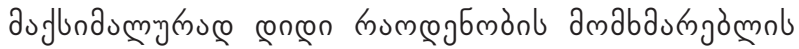

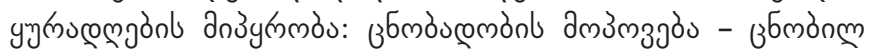
lubge zubonas; 


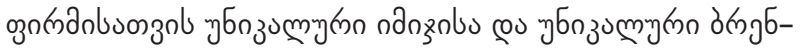
conl gafabs;

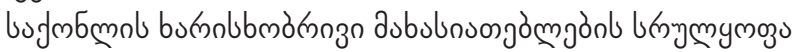

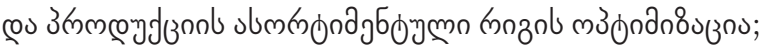

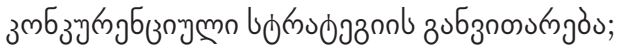

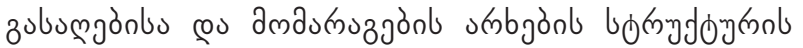

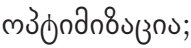

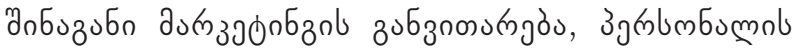

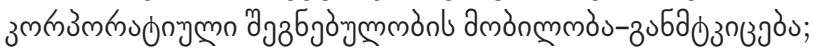

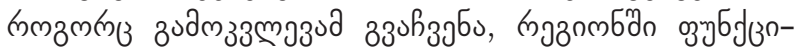

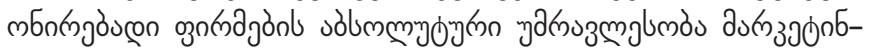

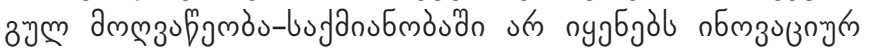

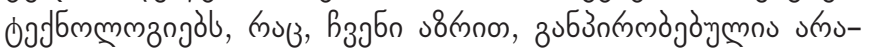

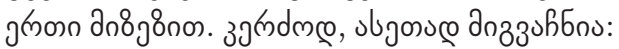

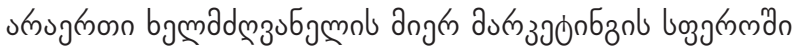

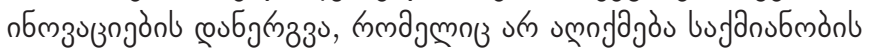

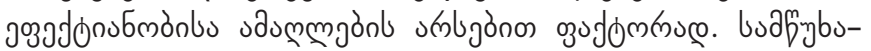

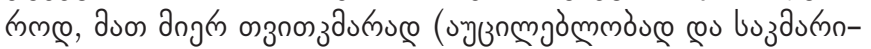
bue) dnпћб

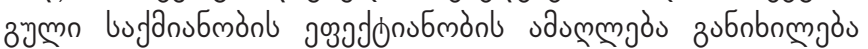

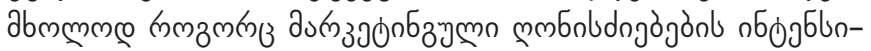

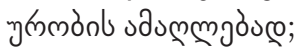

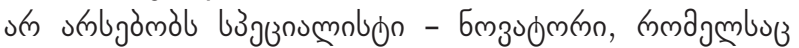

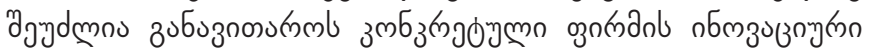

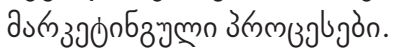

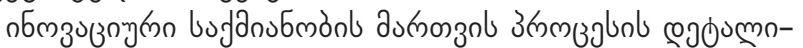

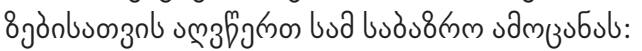

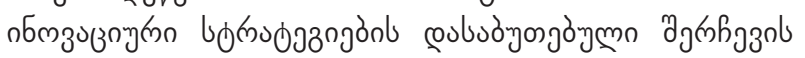
зubbminzongos;

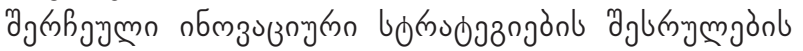

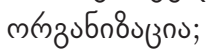

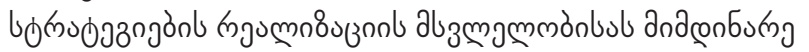

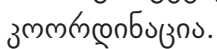

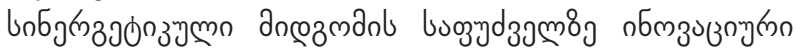

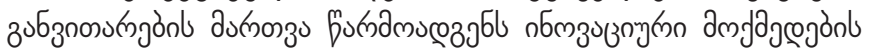

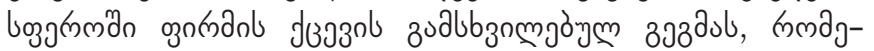

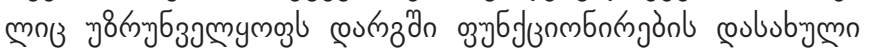

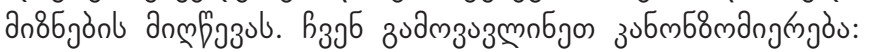

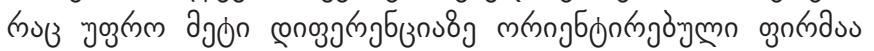

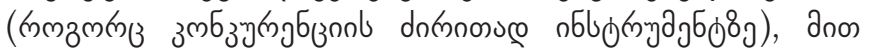

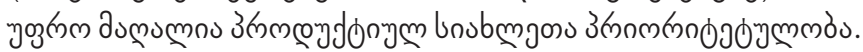

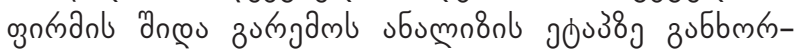

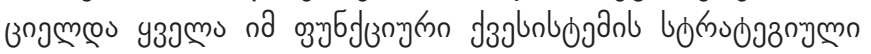

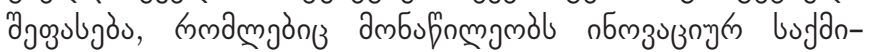

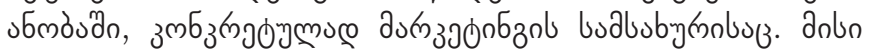

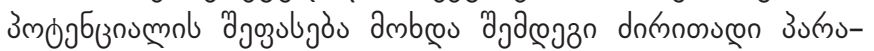
ajoxgònon:

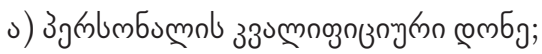

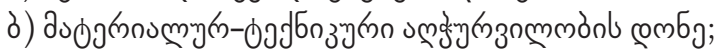

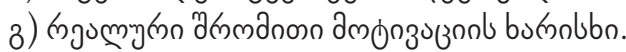

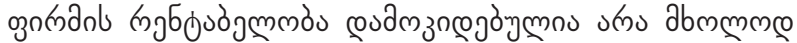

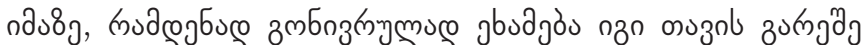

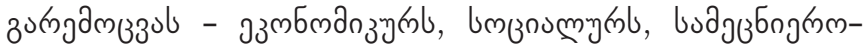

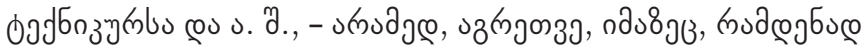

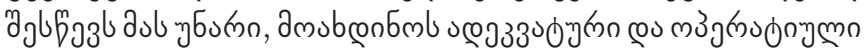

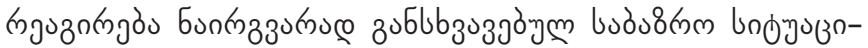

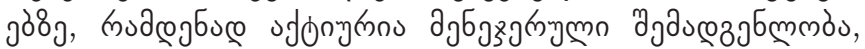

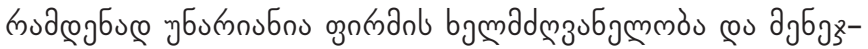

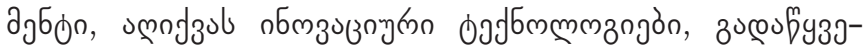

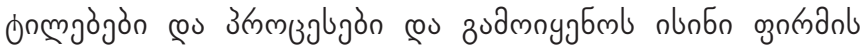

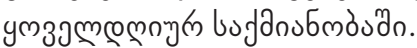

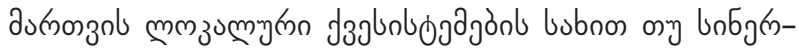

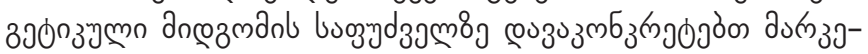

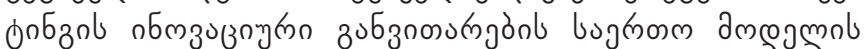

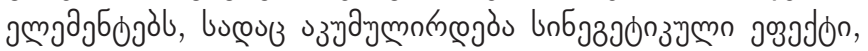

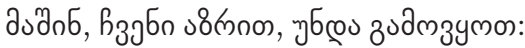

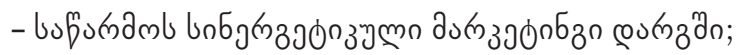

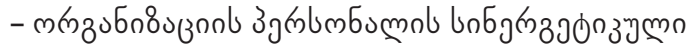

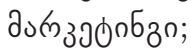

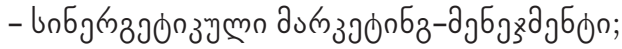

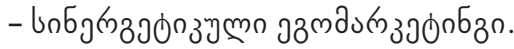

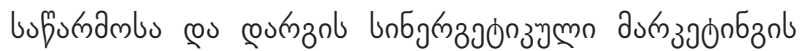

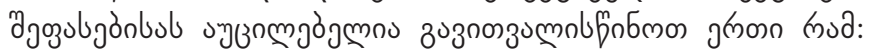

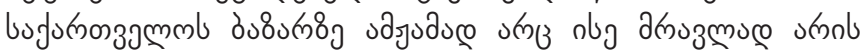

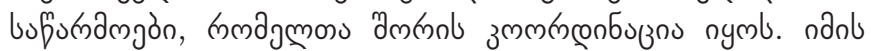

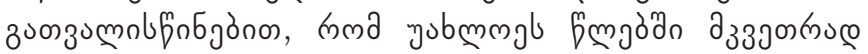

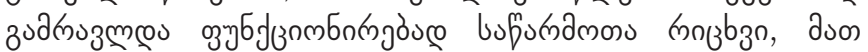

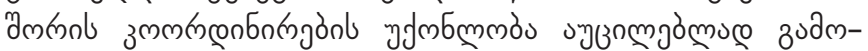

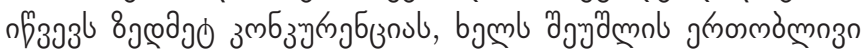

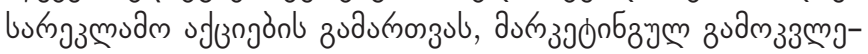

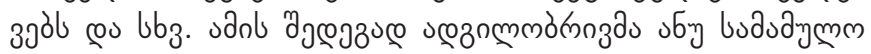

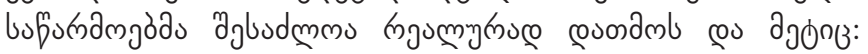

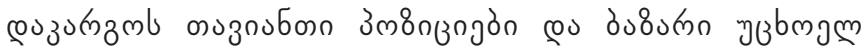

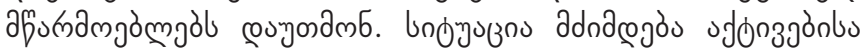

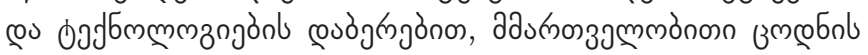

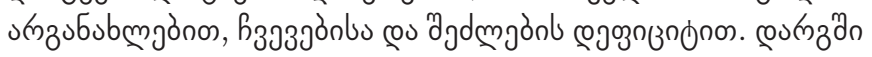

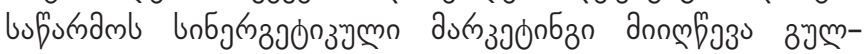

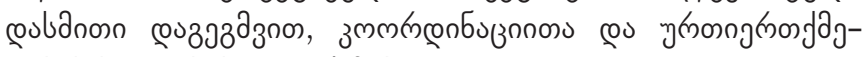

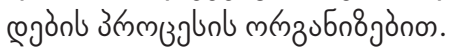

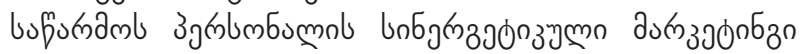

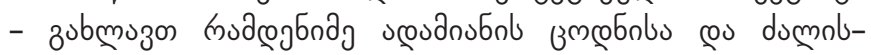

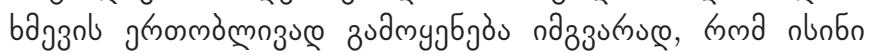

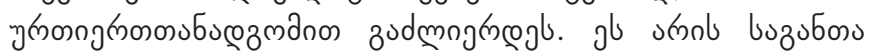

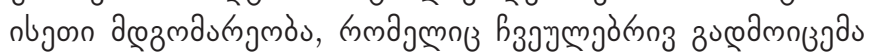

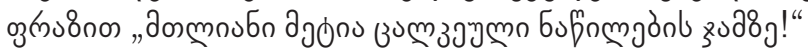

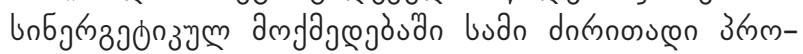

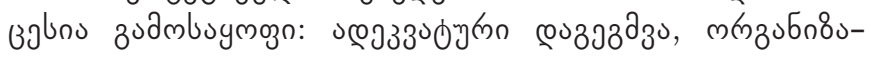

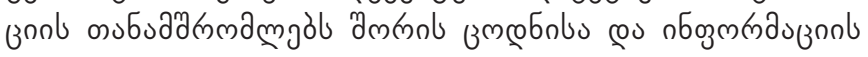

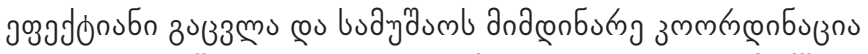

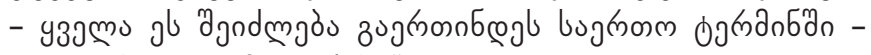
"зलm 


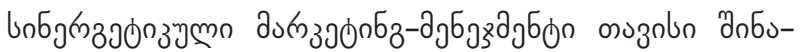

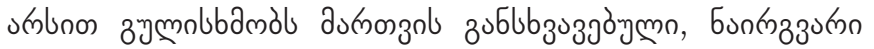

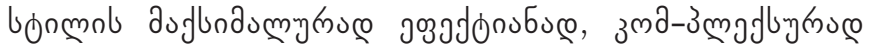

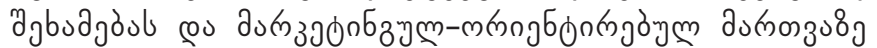

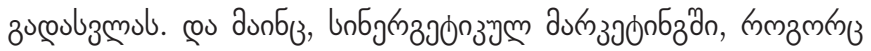

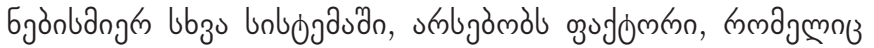

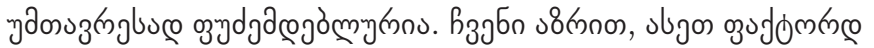

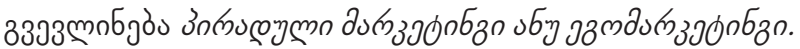

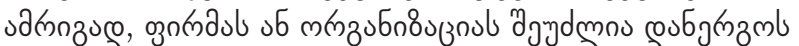

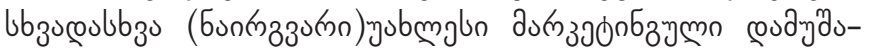

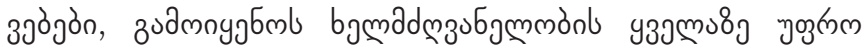

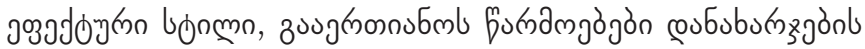

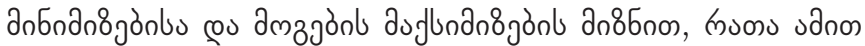

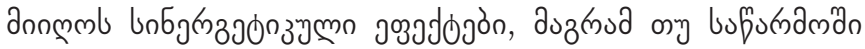

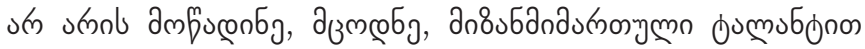

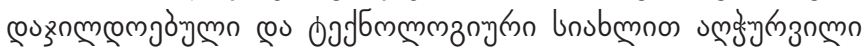

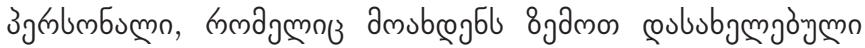

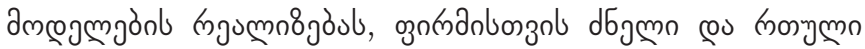

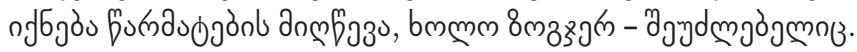

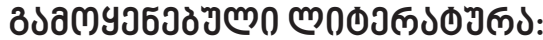

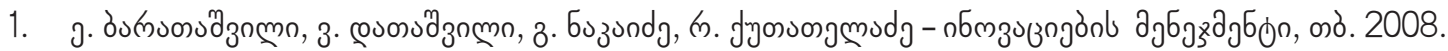

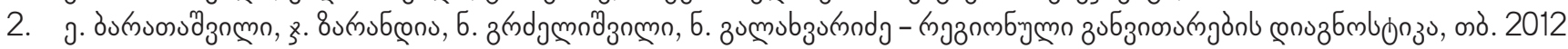

3. Bolton R; (2013), HR as a driver for Organizational Innovation, KPMG cutting through complexity.

4. Barry J., Kevin D., ( 2010), The Global Innovation 1000 "How the top Innovators Keep Winning.Issue 61.

5. The Conference Board CEO CHALLENGE 2015 http://employeeengagement.com/wp-content/uploads/2014/01/2015CEO-Challenge-Conference-Board-Report1.pdf) 


\section{APPROVAL OF SYNERGISTIC APPROACH IN MARKETING OF REGIONAL ENTERPRISES}

NANA NADIRASHVILI

https://doi.org/10.35945/gb.2017.04.024

PhD Student of Technical University of Georgia, Georgia

LELA INASARIDZE

PhD Student of Technical University of Georgia, Georgia

KEYWORDS: SYNERGISTIC APPROACH, INNOVATION, MARKETING SUMMARY

\section{SUMMARY}

During managing the marketing system with scientific methods, especially with synergism and synergetic ideas, we are introduced to new innovative methods as a result of which we get a completely original group. Usage of synergetic ideas helps us to increase management effectiveness, particularly to realize and become aware of important defects and their remedies without special expenditures. Such method makes it possible to conserve-minimize resources and costs. 